\title{
Endpoint Value Derivation Technique
}

National Cancer Institute

\section{Source}

National Cancer Institute. Endpoint Value Derivation Technique. NCI Thesaurus. Code C82866.

A data derivation technique used to calculate a subject's analysis end point value. 